\title{
NODA Presidents
}

Prepared by Mary Jo Fabich, NODA Historian

\begin{tabular}{|c|c|c|}
\hline First Year of Term & President & Institution \\
\hline 1976 & Mike Jones & $\begin{array}{l}\text { State University of New } \\
\text { York at Oswego }\end{array}$ \\
\hline 1978 & Don Perigo & Michigan State University \\
\hline 1980 & Bob Walters & $\begin{array}{l}\text { California Polytechnic State } \\
\text { University }\end{array}$ \\
\hline 1982 & Debbie Shriver & University of Tennessee \\
\hline 1984 & Dave Hansen & University of Nevada - Reno \\
\hline 1986 & Yvonne Schildt & University of the Pacific \\
\hline 1988 & Jim Zakely & $\begin{array}{l}\text { University of Northern } \\
\text { Colorado }\end{array}$ \\
\hline 1990 & Richard Mullendore & $\begin{array}{l}\text { University of North } \\
\text { Carolina - Wilmington }\end{array}$ \\
\hline 1992 & Becky Smith & Otterbein College \\
\hline 1994 & Victor Wilson & Agnes Scott College \\
\hline 1996 & Daniel Robb & Bridgewater State University \\
\hline 1998 & Jeanine Ward-Roof & Clemson University \\
\hline 2000 & Cindy Payne & Northern Arizona University \\
\hline 2002 & Andrene Kaiwi-Lenting & $\begin{array}{l}\text { California Polytechnic State } \\
\text { University }\end{array}$ \\
\hline 2004 & Charlie Andrews & $\begin{array}{l}\text { Florida International } \\
\text { University }\end{array}$ \\
\hline 2007 & Craig Mack & $\begin{array}{l}\text { Massachusetts Bay } \\
\text { Community College }\end{array}$ \\
\hline
\end{tabular}

